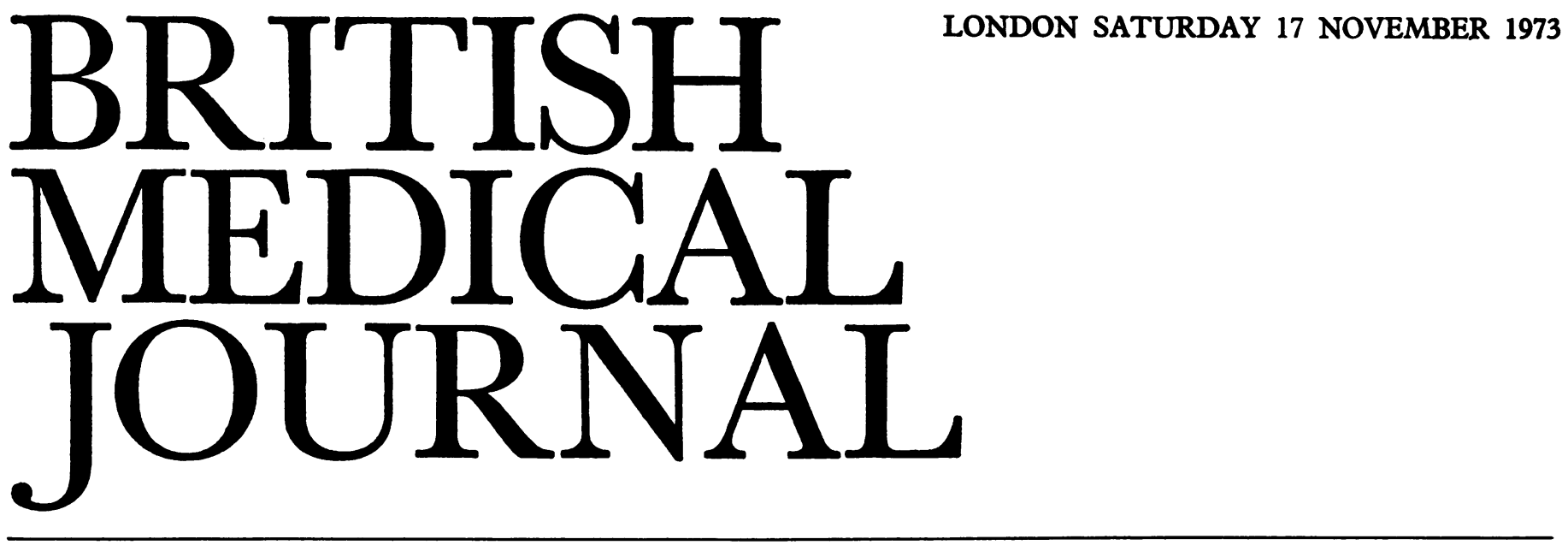

After 25 years of undisputed supremacy within the N.H.S. the teaching hospitals-and especially those in London-are at last facing a serious challenge to their power and influence. Further increase in their numbers of registrars and senior registrars is not only to be halted, it is to be reversed; indeed by March 1974 the number of these posts in teaching institutions in England and Wales is to have been reduced by 59 . This is the initial stage in a series of cuts recommended by the Central Manpower Committee (whose first report is published in the Supplement at p. 43), and whose plan provides for a progressive reduction in junior staff in teaching hospitals over the next decade. The postgraduate centres in London are to lose 161 posts, the London teaching hospitals 328, and the provincial teaching hospitals 176-roughly one third of their total numbers. ${ }^{12}$ Some hospitals are to lose well over a third of their staff-for example, Moorfields is to give up 38 of its 50 registrars (including senior registrars) and the Royal Postgraduate Medical School 56 out of 118 .

This major change in staffing ratios is part of the overall strategy of the Central Manpower Committee, which has set itself the task of evening out the disparity between teaching and non-teaching hospitals and between regions in the numbers of registrar and senior registrar posts, at present heavily concentrated in the London area. The committee is also overseeing the creation of new consultant posts, so that by 1980 there should be a much more nearly uniform doctor/population ratio throughout the hospital regions.

While the committee does not publish the reasoning behind its decisions, it is clear that the redeployment of registrars is also intended to answer the rising body of complaints from regional consultants about shortage of junior staff. The Department of Health has, in fact, had an unenviable task since its agreement with the B.M.A. that the numbers of registrar posts would expand at a slower rate than those of consultants. This agreement was the result of years of lobbying by junior staff, who very reasonably argued that the numbers of training posts in a specialty should be determined by the numbers of consultant vacancies and not by its service needs; but it has meant that since 1969 the numbers of consultants have risen faster than those of junior staff, and inevitably this has led to a steady reduction in the chance of a consultant having a share of a registrar. Added to this has been another equally justifiable series of reforms whereby junior staff have been given more time off duty and better facilities for study leave; and the total effect has been that consultants in non- teaching hospitals have found that in many cases they no longer have experienced junior staff available to assist in maintaining round-the-clock cover for their patients.

Certainly the problems of staffing in district hospitals are real and serious; but how far will the redistribution of registrar posts help to solve them? At present there are about 6,000 registrars and senior registrars in England and Wales (not counting those in psychiatry and mental subnormality). A transfer of 60 from teaching to non-teaching hospitals in the next six months will have a negligible impact, and the full transfer of more than 600 is planned to take effect over a period of ten years. If during that time new consultant posts are created at a rate of $4 \%$ a year and new registrar posts at $2 \frac{1}{2} \%$ a year the consultant/registrar ratio will in fact have worsened by 1980 . Furthermore the transfer is of posts and not of doctors. There is no reason to assume that all the doctors who would have worked at London teaching institutions will necessarily apply for posts in remote and unattractive parts of the country where even now many vacancies have remained unfilled for months and sometimes years.

Clearly for the foreseeable future the main effect of the proposals on district hospitals will be an improvement in morale -something will have been done to redress a balance that most regional consultants consider unfair. What, however, is the likely effect on the teaching hospitals themselves ? Most of the cuts in these hospitals seem likely to be in the major clinical specialties, since the Joint Consultants Committee has agreed $^{3}$ that the "shortage" specialties (such as anaesthetics, radiology, radiotherapy, and venereology) should be protected. The implication seems to be that in the next five years to ten the numbers of registrars in general medicine and surgery in the teaching hospitals could be halved.

These changes must have effects on standards of research, teaching, and care of patients, especially at a time when medical schools are increasing their intake of students. They are also likely to affect the young doctors' choice of career: those who wish to work in an academic environment may be tempted to look outside the United Kingdom for these opportunities if they are not available within the N.H.S.

The first objection that can be made to the proposals of the Central Manpower Committee is, therefore, that their adverse effect on teaching hospitals is likely to be greater than their beneficial effect in district hospitals. Perhaps more important is the serious risk that the controversy about these 
proposals may divert attention from the need for rapid and radical steps to deal with the gorwing problems of staffing in N.H.S. hospitals.

At present two thirds of all senior house officers, half of all registrars, and one quarter of all senior registrars in these hospitals were born overseas. In some specialties-such as neurosurgery, cardiothoracic surgery, and orthopaedics-over two thirds of the registrars are foreign-born doctors. ${ }^{4}$ These figures have two implications: they show that any change in world events that led to a sudden reduction in medical immigration to the United Kingdom could be disastrous for the N.H.S., and they also demonstrate that at present career prospects in a number of specialties are such that hardly any British graduates can be attracted into training posts. At the same time patients are often badly served: casualty services in many parts of the country are quite inadequate, waiting lists are long, and outpatient appointments are delayed for months. News of this gloomy prospect has penetrated into teaching hospitals, and it is perhaps symptomatic of the difficulties of the hospital service that more students than ever before are showing interest in a career in general practice.

Redistribution of registrar posts will do virtually nothing to remedy the serious difficulties in the hospital service, and indeed tinkering with the problem seems more likely just to cause discontent in the teaching hospitals.

There are two separate problems that must be acknowledged by hospital staff-for at present they are not given the attention they deserve. Firstly, registrars are reluctant to take jobs outside teaching hospitals because they know that once they step outside the magic circle they are unlikely to return. There are far too few rotating appointments which require a registrar to spend one year in a regional hospital. Until this situation is changed an ambitious young doctor will prefer to take any job in a teaching hospital-even if it means a year doing laboratory research in which he has little interest-rather than risk sinking without trace in a regional hospital.

Secondly, the freeze on registrar posts must mean that more and more of the routine work in district hospitals will need to be done by part-time medical assistants-married women doctors and general practitioners. The combination of this trend with the steady reduction in the hours worked by junior staff has been responsible for the growing difficulty of arranging cover for emergencies at night and at weekends. It seems inevitable that more emergency work will be done by consultants; but once this change has been accepted it should be possible to devise an equitable system for organizing emergency cover and paying consultants accordingly.

The last decade has seen the Department of Health warily picking its way between pressure groups from the teaching hospitals, hospital junior staff, and regional consultants, and the result has been an unsatisfactory compromise that has been saved from total collapse only by the fortuitous existence of a ready supply of young doctors from overseas. Though it is not an exact parallel, the N.H.S. should profit from the experience of London Transport: reliance on Commonwealth immigrants to solve staffing problems can only be a temporary solution and the supply may dry up very suddenly. Hospital jobs throughout the country must be able to attract graduates fron: our own medical schools if the N.H.S. is to survive, and this is unlikely to be achieved by switching a few registrars from London into the provinces.

1 D.H.S.S. circular to secretaries of all boards of governors. Redistribution of Registrar and Senior Registrar Medical Posts. 23 May 1973. Cited by Bowden, P., and Clare, A. W., Lancet, 2, 857.

2 D.H.S.S. circular to secretaries of all boards of governors. Redistribution of Registrar and Senior Registrar Posts. 8 August 1973.
3 British Medical fournal Supplement, 1973, 4, 37

+ On the State of the Public Health. The Annual Report of the Chief Medical Officer of the Department of Health and Sociai Security for the year 1972. London, H.M.S.O., 1973.

\section{Forms of Colitis}

The first descriptions of ulcerative colitis are lost in early historical writings on chronic non-contagious diarrhoea, but it was probably first referred to as a specifically named disease by Sir Samuel Wilks in 1859 when describing the unfortunate Miss Banks and the morbid appearance of her intestine. ${ }^{1}$ In contrast Crohn's disease has had a more precise historical passage, landmarks being Crohn's own paper in $1932^{2}$ and that by H. E. Lockhart-Mummery and B. C. Morson in $1960^{3}$ on its colonic lesions.

In their classical forms ulcerative colitis and Crohn's disease are easily distinguished on clinical, radiological, and pathological criteria. ${ }^{4}$ The distinction has no aetiological basis, and therefore the diagnosis, though clear-cut at either end of the spectrum, leads to difficulties in the middle ground, even to the extent that they have been considered variants of a single disease. The confusion is partly because no one feature, clinical or pathological, is either invariably present or invariably absent. Non-caseating giant cell granulomata, which most people accept as confirming the diagnosis of Crohn's disease, occur in only about $50 \%$ of otherwise typical cases, ${ }^{5}$ and even these have been described in ulcerative colitis. ${ }^{6}$ Thus at present, while there is no diagnostic test to distinguish Crohn's disease from ulcerative colitis, the separation has to be based on a wide variety of criteria. In this respect a painstaking study of $M . G$. Cook and M. F. Dixon ${ }^{7}$ is of considerable interest. They chose 95 pathological features, recorded the observer variation in recognizing these features, and tabulated them in terms of their diagnostic value in distinguishing Crohn's disease from ulcerative colitis. They studied material from 50 cases of Crohn's disease and 50 cases of ulcerative colitis, all with a confident clinical diagnosis. They concluded that along with certain other features linear ulceration and deep fissures seen macroscopically, together with an aggregated inflammatory pattern and sarcoid-like granulomata, are the best indicators of Crohn's disease. These were not seen in ulcerative colitis, and there was high observer agreement on them. A healed granular mucosa, the absence of fissures, irregular glands, and continuous inflammation have high diagnostic value for ulcerative colitis, being features of all their cases. But crypt abscesses, lymphangiectasia, and submucosal oedema were not of great value as is sometimes held. While 18 of the 19 cases of Crohn's disease showed transmural inflammation, so did 4 of the 23 cases of ulcerative colitis. It is salutary to realize that ${ }^{8}$ Hadfield, writing on Crohn's disease in 1939, emphasizes almost the same features. This highlights the feeling that routine histological examination of operative material may have reached its limit and more discriminating tests are required, perhaps from other pathological disciplines.

Histochemical techniques show mainly non-specific changes in both diseases, a reflection of epithelial cell regeneration. But observations of epithelial mucins have been rewarding. They are more reduced in ulcerative colitis than in Crohn's disease. ${ }^{9}$ This has also been shown to have a surprisingly high discriminative value in routine histology, expressed as goblet cell depletion. ${ }^{10}$ Electron microscopy has not yet provided findings of major diagnostic importance. Some differences are present, but their significance has still to be determined. 